\title{
ANALISIS PENGARUH GAYA KEPEMIMPINAN TERHADAP KINERJA SPG PD. SUMBER JAYA
}

\author{
Teguh Sriwidadi ${ }^{1}$; Oey Charlie $^{2}$ \\ ${ }^{1,2}$ Jurusan Manajemen, Fakultas Ekonomi dan Bisnis, Universitas Bina Nusantara \\ Jln. K.H. Syahdan No. 9, Palmerah, Jakarta Barat 11480
}

\begin{abstract}
PD Sumber Jaya is a company engaged in the leather goods and accessories retailer that sells Braun Buffel brand which has several stores in Jakarta, Surabaya, and also a number of outlets throughout Indonesia. In each outlet is guarded by several Sales Promotion Girls (SPG). The purpose of this study is to analyze the influence of leadership style on the performance of SPG PD. Sumber Jaya. The method of analysis used in this study is Test Validity, Test Reliability, Mean, Pearson Correlation, and Regression . Data obtained from SPG assessment of managers by filling out the questionnaire that has been provided by using a Likert scale. The results achieved in this research is the leadership style which is run by managers PD. Sumber Jaya is a type of democratic and individual leadership styles have a strong influence of (0.195) or $19.50 \%$ and the direction (+) on the performance of SPG PD. Sumber Jaya.Leadership style has a fairly strong relationship $(r y \times 1=0.442)$ on the performance of SPG.
\end{abstract}

Keywords: leadership style, SPG performance

\begin{abstract}
ABSTRAK
PD Sumber Jaya merupakan sebuah perusahaan yang bergerak di bidang retail leather goods and accessories yang menjual merk dagang Braun Buffel yang memiliki beberapa toko di Jakarta, Surabaya, dan juga sejumlah outlet di seluruh Indonesia. Di setiap outlet itu dijaga oleh beberapa Sales Promotion Girls (SPG). Tujuan penelitian ini adalah menganalisa pengaruh gaya kepemimpinan terhadap kinerja SPG PD. Sumber Jaya. Metode analisa yang digunakan dalam penelitian ini adalah Uji Validitas, Uji Reabilitas, Mean, Korelasi Pearson, dan Regresi Sederhana. Data diperoleh dari penilaian SPG terhadap manajer dengan mengisi kuesioner yang telah disediakan dengan menggunakan skala likert. Hasil yang dicapai dalam penelitian ini adalah gaya kepemimpinan yang dijalankan oleh manajer PD. Sumber Jaya adalah tipe demokratis dan secara individu gaya kepemimpinan memiliki pengaruh yang cukup kuat sebesar (0.195) atau $19.50 \%$ dan searah (+) terhadap kinerja SPG PD. Sumber Jaya. Gaya Kepemimpinan memiliki hubungan yang cukup kuat $($ ryx1 = 0.442) terhadap kinerja SPG.
\end{abstract}

Kata kunci: gaya kepemimpinan, kinerja SPG 


\section{PENDAHULUAN}

\section{Latar Belakang Masalah}

Keberhasilan suatu organisasi sangat dipengaruhi oleh peran pemimpinnya. Pemimpin merupakan motor penggerak bagi organisasi untuk dapat menjalankan setiap aktivitas organisasi dalam mencapai tujuan-tujuan yang ingin dicapai oleh organisasi. Seorang pemimpin harus mampu memberikan suatu arahan terhadap para karyawan agar kinerja karyawan baik. Peran dari motivasi kerja pun sangat mendukung kinerja karyawan. Jadi, seorang pemimpin pun harus dapat memperhatikan hal-hal apa yang dapat memberikan motivasi kerja terhadap bawahan agar kinerja bawahan dapat menjadi lebih baik.

PD Sumber Jaya adalah perusahaan yang bergerak di bidang retail leather goods and accessories. Perusahaan ini berdiri sejak tahun 1988 dengan menjual merk dagang Braun Buffel dan Renoma. Kompetitor utama perusahaan ini adalah Pierre Cardin, Picard, Mont Blanc dan Bonia. Perusahaan ini memiliki 5 (lima) buah toko di Jakarta, 1 (satu) buah toko di Surabaya, dan juga memiliki 49 outlet di seluruh Indonesia. Di setiap outlet itu dijaga oleh beberapa SPG. Peneliti melakukan wawancara dengan pimpinan perusahaan, untuk mengetahui kinerja para SPG yang ada di seluruh Jakarta, dan untuk mengetahui kepemimpinan manajer supervisor dan apakah gaya kepemimpinan memengaruhi kinerja SPG.

\section{Perumusan Masalah}

Penelitian ini dilakukan untuk mengetahui gaya kepemimpinan yang diterapkan oleh manajer PD. Sumber Rizki Jaya, kinerja SPG, serta pengaruh gaya kepemimpinan terhadap kinerja SPG.

\section{Landasan Teori}

\section{Pengertian Kepemimpinan dan Pemimpin}

Definisi kepemimpinan menurut Robbins \& Judge (2008) menyebutkan bahwa kepemimpinan merupakan kemampuan untuk memengaruhi suatu kelompok guna mencapai sebuah visi atau serangkaian tujuan yang ditetapkan. Menurut Rivai dan Mulyadi (2009), kepemimpinan adalah sebagai proses mengarahkan dan memengaruhi aktivitas-aktivitas yang ada hubungannya dengan pekerjaan para anggota kelompok. Tiga implikasi penting yang terkandung dalam hal ini yaitu: (1) kepemimpinan melibatkan orang lain baik itu bawahan maupun pengikut; (2) kepemimpinan melibatkan pendistribusian kekuasaan antara pemimpin dan anggota kelompok secara seimbang, karena anggota kelompok bukanlah tanpa daya; (3) adanya kemampuan untuk menggunakan bentuk kekuasaan yang berbeda untuk memengaruhi tingkah laku pengikutnya melalui berbagai cara. Dari pengertian kepemimpinan tersebut dapat disimpulkan bahwa kepemimpinan merupakan kemampuan lebih yang dimiliki oleh seseorang untuk memengaruhi dan membujuk orang-orang yang ada dalam lingkungannya, agar mereka bersedia bekerja untuk mencapai tujuan yang diinginkan.

Menurut Kartono (2006) pemimpin mempunyai bermacam-macam pengertian. Beberapa definisi tersebut, yaitu (1) pemimpin adalah seorang pribadi yang memiliki kecakapan dan kelebihan, khususnya di satu bidang, sehingga mampu memengaruhi orang lain untuk bersama-sama melakukan aktivitas-aktivitas tertentu, demi pencapaian satu atau beberapa tujuan; (2) menurut Fairchild, yang dikutip oleh Kartono (2006), pemimpin dalam arti luas ialah seorang yang memimpin dengan jalan memprakarsai tingkah laku sosial dengan mengatur, mengarahkan, mengorganisasikan atau mengontrol usaha/upaya orang lain atau melalui prestige, kekuasaan atau posisi. Dalam arti sempit, pemimpin ialah seorang yang membimbing, memimpin dengan bantuan kualitas persuasifnya, dan 
akseptansi/penerimaan secara sukarela oleh para pengikutnya; (3) menurut Allee, yang dikutip oleh Kartono (2006), leader ... a guide; a conductor; a commander (pemimpin itu ialah pemandu, penunjuk, penuntun, komandan).

\section{Jenis-Jenis Pemimpin}

Jenis pemimpin terbagi menjadi dua, yaitu pemimpin formal dan pemimpin informal. Pemimpin formal adalah orang yang oleh organisasi/lembaga tertentu ditunjuk sebagai pemimpin, berdasarkan keputusan dan pengangkatan resmi untuk memegang suatu jabatan dalam struktur organisasi, dengan segala hak dan kewajiban yang berkaitan dengannya, untuk mencapai sasaran organisasi. Sementara itu, pemimpin informal adalah orang yang tidak mendapatkan pengangkatan formal sebagai pemimpin, namun karena memiliki sejumlah kualitas maka mencapai kedudukan sebagai orang yang mampu memengaruhi kondisi psikis dan perilaku suatu kelompok atau masyarakat.

\section{Sifat-Sifat Pemimpin}

Menurut Tead, dalam tulisannya yang dikutip oleh Kartono (2006), terdapat 10 sifat pemimpin, yaitu: (1) energi jasmaniah dan mental (physical and nervous energy); (2) kesadaran akan tujuan dan arah (a sense of purpose and direction); (3) antusiasme (enthusiasm; semangat, kegairahan, kegembiraan yang besar); (4) keramahan dan kecintaan (friendliness and affection); (5) integritas (integrity, keutuhan, kejujuran, ketulusan hati); (6) penguasaan teknis (technical mastery); (7)

ketegasan dalam mengambil keputusan (decisiveness); (8) kecerdasan (intelligence); (9) keterampilan mengajar (teaching skill); (10) kepercayaan (faith).

Sedangkan menurut Terry, yang dikutip oleh Kartono (2006), terdapat 10 sifat pemimpin yang unggul, yaitu kekuatan, kekuatan badaniah dan rohaniah, stabilitas emosi, pengetahuan tentang relasi insani, kejujuran, objektif, dorongan pribadi, keterampilan berkomunikasi, kemampuan mengajar, keterampilan sosial, dan kecakapan teknis atau kecakapan manajerial.

\section{Gaya Kepemimpinan}

Gaya kepemimpinan menurut Thoha (2007) adalah cara yang digunakan oleh seorang pemimpin dalam memengaruhi bawahan agar mau melaksanakan tugas dan kewajibannya sesuai dengan yang diharapkan agar tercapai tujuan yang telah ditentukan sebelumnya.

Tabel 1 Empat Gaya Dasar Kepemimpinan

\begin{tabular}{ll}
\hline $\begin{array}{l}\text { Tinggi Perhatian dan } \\
\text { Rendah Pengarahan (G3) }\end{array}$ & $\begin{array}{l}\text { Tinggi Pengarahan dan Tinggi } \\
\text { Perhatian(G2) }\end{array}$ \\
$\begin{array}{ll}\text { Rendah pengarahan dan } \\
\text { Rendah Perhatian (G4) }\end{array}$ & $\begin{array}{l}\text { Tinggi Pengarahan dan Rendah } \\
\text { Perhatian (G1) }\end{array}$
\end{tabular}

Sumber: Miftah Thoha, kepemimpinan dalam manajemen ( 2007, p27)

Berdasarkan Tabel 1, G1 adalah pemimpin yang banyak memberikan pengarahan namun sedikit dukungan.; G2 adalah pemimpin yang banyak mengarahkan dan banyak memberikan dukungan; G3 adalah pemimpin ini banyak memberikan dukungan namun sedikit pengarahan; G4 adalah pemimpin yang memberikan sedikit dukungan dan sedikit pengarahan. Menurut Kartono (2006), gaya kepemimpinan sebagai suatu pola perilaku manajemen profesional yang dirancang untuk memadukan minat dan usaha pribadi serta organisasi untuk mencapai tujuan. 
Ada 3 macam kepemimpinan, yaitu: (1) kepemimpinan authoritarian (authocratic), pemimpin mengutamakan kekuatan dari posisi formalnya: kurang memerhatikan kebutuhan bawahan, lebih menciptakan penyelesaian tugas, semua aktivitas ditentukan oleh atasan, komunikasi hanya satu arah $\rightarrow$ ke bawah saja; (2) kepemimpinan partisipaty (democratie), melibatkan bawahan dalam perencanaan/ pengambilan keputusan, lebih memerhatikan kepada bawahan $\rightarrow$ mencapai tujuan organisasi, menekankan 2 hal $\rightarrow$ bawahan dan tugas; (3) kepemimpinan laisser - faire, pemimpin membiarkan bawahannya untuk mengatur dirinya sendiri, manajer hanya menentukan kebijaksanaan dan tujuan umum, bawahan dapat mengambil keputusan yang relevan dan mencapai tujuan dalam segala hal yang mereka anggap cocok.

\section{Pengertian Kinerja}

Pengertian kinerja atau prestasi kerja diberi batasan oleh Maier sebagai kesuksesan seseorang di dalam melaksanakan suatu pekerjaan. Lebih tegas lagi Lawler \& Poter (1967) menyatakan bahwa kinerja adalah successfull role achievement yang diperoleh seseorang dari perbuatan-perbuatannya. Dari batasan tersebut dapat disimpulkan bahwa kinerja adalah hasil yang dicapai seseorang menurut ukuran yang berlaku untuk pekerjaan yang bersangkutan. Sedang Suprihanto menyatakan bahwa kinerja atau prestasi kerja seseorang karyawan pada dasarnya adalah hasil kerja seseorang karyawan selama periode tertentu dibandingkan dengan kemungkinan, misalnya standar, target atau sasaran atau kinerja yang telah ditentukan terlebih dahulu dan telah disepakati bersama.

Prestasi kerja atau kinerja berasal dari kata job performance (prestasi kerja atau prestasi sesungguhnya yang pernah dicapai seseorang). Pengertian kinerja (prestasi kerja) adalah hasil kerja secara kualitas dan kuantitas yang dicapai oleh seorang pegawai dalam melaksanakan tugasnya sesuai dengan tanggung jawab yang diberikan kepadanya. Faktor-faktor yang memengaruhi pencapaian kinerja adalah faktor kemampuan (ability) dan faktor motivasi. Hal ini sesuai dengan pendapat Davis \& Newstroom (1985), yang memutuskan bahwa: human performance $=$ ability + performance; motivation $=$ attitude + situation; ability $=$ knowledge + skill. Berdasarkan pendapat Vroom dalam Luthans (2006) tingkat sejauh mana keberhasilan seseorang dalam menyelesaikan pekerjaannya disebut level of performance. Biasanya orang yang level of performance-nya tinggi disebut sebagai orang yang produktif, dan sebaliknya orang yang levelnya tidak mencapai standar dikatakan sebagai tidak produktif atau berperforma rendah.

\section{Faktor-faktor yang Memengaruhi Kinerja}

Faktor-faktor yang memengaruhi kinerja, yaitu: (1) variabel individual: kemampuan dan keterampilan: mental dan fisik; latar belakang: keluarga, tingkat sosial, penggajian; demografis: umur, asal-usul, jenis kelamin. (2) Variabel organisasional: sumberdaya, kepemimpinan, imbalan, struktur, dan disain pekerjaan. (3) Variabel psikologis, terdiri dari: persepsi, sikap, kepribadian, belajar, dan motivasi.

\section{Uji Validitas}

Uji validitas yaitu untuk menguji seberapa baik suatu instrumen yang dibuat mengukur konsep tertentu yang ingin diukur (Sekaran, 2006).

\section{Uji Reliabilitas}

Reliabilitas (keandalan) suatu pengukuran merupakan indikasi mengenai stabilitas dan konsistensi di mana instrument mengukur konsep dan membantu menilai ketepatan sebuah pengukuran (Sekaran, 2006). 


\section{Regresi Sederhana}

Regresi sederhana digunakan untuk mengetahui keadaan (naik turunnya) variabel terikat (dependent variable) dengan naik turunnya variabel bebas (independent variable).

Persamaan regresi sederhana

$$
\mathrm{Y}=\mathrm{a}+\mathrm{bX}
$$

Di mana:

$\mathrm{Y}=$ variabel terikat

$\mathrm{X}=$ variabel bebas

$\mathrm{a}$ dan $\mathrm{b}=$ koefisien regresi

\section{METODOLOGI PENELITIAN}

Tabel 2 Desain Penelitian

\begin{tabular}{lllll}
\hline \multicolumn{1}{c}{ Tujuan } & \multicolumn{1}{c}{$\begin{array}{c}\text { Jenis dan metode } \\
\text { penelitian }\end{array}$} & Unit Analisis & Time Horizon \\
\hline T-1 : gaya kepemimpinan & Deskriptif - Survei & Individu $\rightarrow$ SPG & Cross-sectional \\
T2 : kinerja SPG & Deskriptive - Survei & Individu $\rightarrow$ SPG & Cross-sectional \\
$\begin{array}{l}\text { T3: gaya kepemimpinan } \\
\text { terhadap kinerja SPG }\end{array}$ & Asosiatif - Survei & Individu $\rightarrow$ SPG & Cross-sectional \\
\hline
\end{tabular}

\section{Jenis dan Sumber Data Penelitian} kuesioner)

Jenis data untuk semua variabel adalah data kuantitatif. Sumber data adalah primer (dari

\section{Teknik Pengumpulan Data}

Sumber data primer yaitu wawancara dan kuesioner. Sementara itu, data-data sekunder diperoleh melalui studi literatur dengan cara melihat, membaca, dan mencatat buku-buku, tesis, internet dan jurnal.

\section{Teknik Pengambilan Sampel}

Teknik pengambilan sampel yang diterapkan dalam penelitian ini adalah probability sampling, dan simple random sampling.

\section{Metode Analisis}

$\mathrm{T} 1$ dan $\mathrm{T} 2$, jenis penelitian deskriptif, teknik analisis yaitu mean dan diagram histogram. T3 jenis asosiatif, teknik analisis yaitu regresi sederhana.

\section{Skala Interval}

Bentuk pertanyaan yang digunakan dalam kuesioner adalah structured non disquised yaitu bentuk pertanyaan merupakan kombinasi pilihan ganda yang berpedoman pada Skala Likert yang digunakan untuk mengukur sikap, pendapat, dan persepsi bagi seorang responden. Bentuk penilaian jawaban kuesioner menggunakan pembobotan dengan 5 buah skala, yaitu sangat tidak setuju: bobot nilai 1; tidak setuju: bobot nilai 2; ragu-ragu: 3; setuju: bobot nilai 4; sangat setuju: bobot nilai 5 . 


\section{HASIL DAN PEMBAHASAN}

\section{Uji Validitas}

Uji validitas untuk tiap instrumen dilakukan dengan menggunakan rumus korelasi pearson product moment dengan mengkorelasikan skor tiap butir pernyataan (sebagai variabel $\mathrm{X}$ ) dengan skor total (variabel Y). Dasar pengambilan keputusan pada uji validitas ini adalah: (1) jika $r$ hasil $>0,19$, maka butir atau pernyataan tersebut valid; (2) jika $\mathrm{r}$ hasil $>0,19$, maka butir atau pernyataan tersebut tidak valid. Nilai $r$ hasil didapat dari hasil perhitungan korelasi Pearson Product Moment antara skor tiap butir pernyataan dengan skor total.

Tabel 3 Uji Validitas Gaya Kepemimpinan Tipe Birokrat

\begin{tabular}{ccc}
\hline & Koefisien Korelasi & Keterangan \\
\hline P1 & 0.348 & Valid \\
P2 & 0.367 & Valid \\
P3 & 0.351 & Valid \\
P4 & 0.188 & Tidak Valid \\
P5 & 0.389 & Valid \\
\hline
\end{tabular}

Sumber: Hasil Pengolahan Data, 2010

Tabel 4 Uji Validitas Gaya Kepemimpinan Tipe Otoriter

\begin{tabular}{ccc}
\hline & Koefisien Korelasi & Keterangan \\
\hline P1 & 0.395 & Valid \\
P2 & 0.507 & Valid \\
P3 & 0.462 & Valid \\
P4 & 0.342 & Valid \\
P5 & 0.405 & Valid \\
\hline
\end{tabular}

Sumber : Hasil Pengolahan Data, 2010

Tabel 5 Uji Validitas Gaya Kepemimpinan Tipe Demokratis

\begin{tabular}{ccc} 
& Koefisien Korelasi & Keterangan \\
\hline P1 & 0.421 & Valid \\
P2 & 0.542 & Valid \\
P3 & 0.330 & Valid \\
P4 & 0.329 & Valid \\
P5 & 0.409 & Valid \\
\hline
\end{tabular}

Sumber : Hasil Pengolahan Data, 2010

Hasil uji di atas menyatakan bahwa pernyataan yang terdapat pada kuesioner yang menilai ke 3 dimensi atau sub variabel yang mewakili gaya kepemimpinan terdapat 1 pertanyaan yang tidak valid yaitu 1 pernyataan pada gaya kepemimpinan birokrat, dikarenakan nilai $r$ hasil pernyataan lebih kecil dari $r$ table yaitu 0.19 dan sisanya sebanyak 14 pernyataan yang valid, karena nilai $r$ hasil pernyataan bernilai lebih besar dari $\mathrm{r}$ tabel yaitu 0.19. Dengan adanya pernyataan yang tidak valid, maka pernyataan yang tidak valid tersebut dibuang sehingga pernyataan yang ada dalam kuesioner dapat digunakan untuk mengumpulkan data yang sebenarnya. 
Tabel 6 Uji Validitas Kinerja SPG PD. Sumber Jaya

\begin{tabular}{ccc}
\hline & Koefisien Korelasi & Keterangan \\
\hline P1 & 0.573 & Valid \\
P2 & 0.349 & Valid \\
P3 & 0.666 & Valid \\
P4 & 0.495 & Valid \\
P5 & 0.352 & Valid \\
P6 & 0.348 & Valid \\
P7 & 0.532 & Valid \\
P8 & 0.645 & Valid \\
\hline Sumber
\end{tabular}

Sumber : Hasil Pengolahan Data, 2010

Berdasarkan hasil uji di atas maka dapat disimpulkan bahwa pernyataan yang terdapat pada pernyataan kuesioner yang menilai kinerja SPG PD. Sumber Jaya merupakan pernyataan yang valid diperlihatkan dengan $r$ hasil seluruh pertanyaan lebih besar daripada $r$ tabel. Dengan validnya seluruh pertanyaan, maka seluruh pertanyaan ini dapat digunakan dalam kuesioner untuk mengumpulkan data yang sebenarnya.

\section{Uji Reliabilitas}

Uji reliabilitas diperlukan untuk mengukur tingkat keandalan kuesioner. Untuk itu, dilakukan uji reliabilitas internal pada instrumen penelitian dengan menggunakan teknik reliabilitas dengan metode Alpha. Uji reliabilitas menggunakan metode Alpha dilakukan pada instrumen pertanyaan yang menggunakan kategorisasi jawaban dengan skala bukan 0 dan 1, seperti skala 1 sampai 5, 1 sampai 7 atau -3 sampai 3. teknik alpha dilakukan dengan memperhitungkan varians butir pertanyaan.

Dasar pengambilan keputusan pada uji reliabilitas ini yaitu: (1) bila Cronbach's Alpha $>0.600$ maka kuesioner yang diuji reliabel; (2) bila Cronbach's Alpha $<0.600$ maka kuesioner yang diuji tidak reliabel. Pada teknik Alpha, $r$ hasil didapatkan dengan memperhitungkan varians yang kemudian dimasukkan pada rumus Alpha. Sedangkan nilai $r$ tabel didapat secara teoritis di mana nilai $r$ tabel sebesar 0.600 .

\section{Gaya Kepemimpinan}

Gaya Kepemimpinan manajer PD. Sumber Jaya yang ditunjukkan melalui Tabel 7 berikut.

Tabel 7 Uji Reliabilitas Variabel Gaya Kepemimpinan

\begin{tabular}{cc}
\hline Croncbach's Alpha & N of items \\
\hline 0.770 & 15 \\
\hline Sumber: Hasil Pengolahan Data, 2010
\end{tabular}

Kuesioner variable gaya kepemimpinan yang mewakili 3 dimensi dan 15 pertanyaan dapat dinyatakan sebagai kuesioner yang reliabel atau handal, ditunjukkan dengan $r$ hasil sebesar 0.769 .

\section{Kinerja SPG}

PD Sumber Jaya yang ditunjukkan melalui Tabel 8 berikut. 
Tabel 8 Uji Reliabilitas Variabel Kinerja SPG

\begin{tabular}{cc}
\hline Croncbach's Alpha & N of items \\
\hline 0.761 & 8 \\
\hline Sumber: Hasil Pengolahan Data, 2010
\end{tabular}

Kuesioner Kinerja SPG yang mewakili 8 pertanyaan dapat dinyatakan sebagai kuesioner yang reliabel atau handal, ditunjukkan dengan $r$ hasil sebesar 0.783

\section{Analisis Gaya Kepemimpinan PD Sumber Jaya}

Gaya kepemimpinan yang dimiliki oleh manajer PD Sumber Jaya dapat dianalisa dengan melihat penilaian SPG terhadap atasannya dari ke 3 indikator yaitu tipe birokrat, tipe otoriter dan tipe demokratis.

\section{Analisis Gaya Kepemimpinan Dengan Tipe Birokrat}

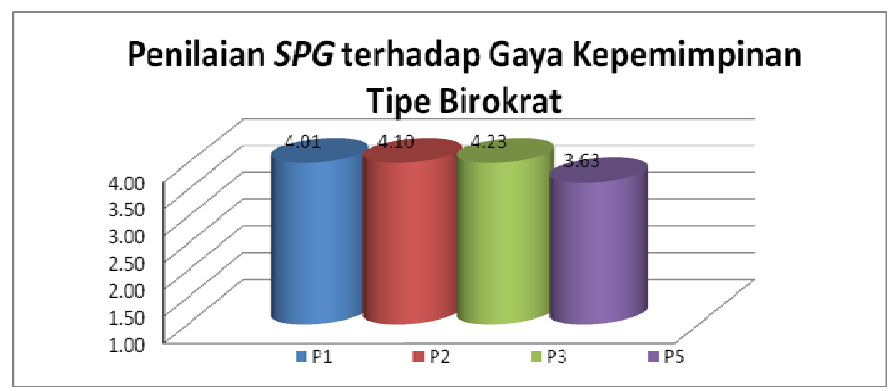

Gambar 1 Gaya Kepemimpinan Dengan Tipe Birokrat

P1 berarti berdasarkan gambar 1, SPG PD. Sumber Jaya menilai setuju (4.01) bahwa pimpinannya mendorong mereka agar pekerjaan dijalankan sesuai jadwal. Dalam P2, berdasarkan gambar 1, SPG PD. Sumber Jaya menilai setuju (4.10) bahwa pimpinan mendorong mereka agar mematuhi standar prosedur yang ada. P3 berarti berdasarkan gambar 1, SPG menilai sangat setuju (4.23) bahwa pimpinannya meminta untuk mematuhi norma dan aturan yang ada di perusahaan. P5 berarti berdasarkan gambar 1, SPG menilai setuju (3.63) bahwa mereka merasa sulit menjalankan pekerjaan karena aturan-aturan yang ada. Secara umum, dari penilaian SPG PD. Sumber Jaya terhadap gaya kepemimpinan dengan tipe birokrat pada manajer PD. Sumber Jaya adalah setuju (3.99), bahwa gaya kepemimpinan dari manajer PD. Sumber Jaya adalah dengan tipe birokrat.

\section{Analisis Gaya Kepemimpinan dengan Tipe Otoriter}

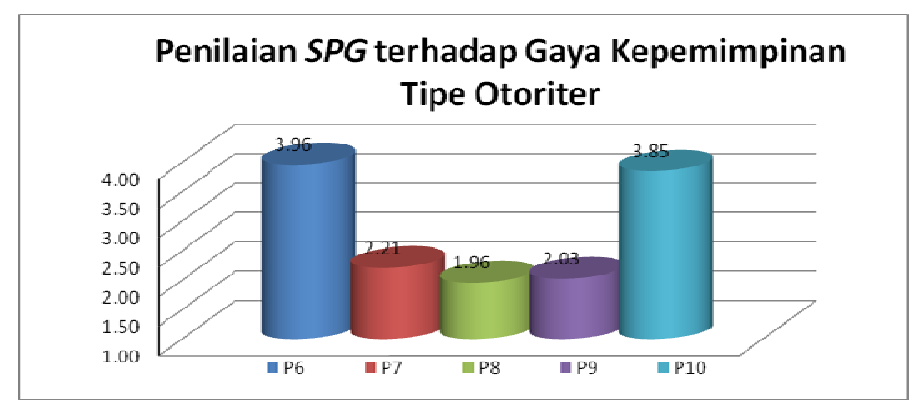

Gambar 2 Gaya Kepemimpinan dengan Tipe Otorier 
P6 berarti berdasarkan Gambar 2, SPG menilai setuju $(3,96)$ pimpinan mereka memutuskan apa yang harus mereka lakukan dan bagaimana menjalankannya. P7 berarti berdasarkan gambar 2, SPG menilai tidak setuju $(2,21)$ pimpinan mereka mengambil keputusan yang membuat pekerjaan mereka tidak menyenangkan. Sementara itu, P8 berarti berdasarkan gambar 2, SPG menilai tidak setuju $(1,96)$ pimpinan mereka bertindak tanpa memerhatikan kondisi mereka. P9 berarti berdasarkan gambar 2, SPG menilai tidak setuju $(2,03)$ pimpinan mereka tidak mendengarkan saran bawahan. P10 berarti berdasarkan gambar 2, SPG menilai setuju $(3,85)$ keputusan pimpinan harus diterima dan dijalankan oleh bawahan. Secara umum, dari penilaian SPG terhadap gaya kepemimpinan dengan tipe otoriter pada manajer PD. Sumber Jaya adalah ragu-ragu (2.80), bahwa gaya kepemimpinan dari manajer PD. Sumber Jaya adalah dengan tipe otoriter.

\section{Analisa Gaya Kepemimpinan dengan Tipe Demokratis}

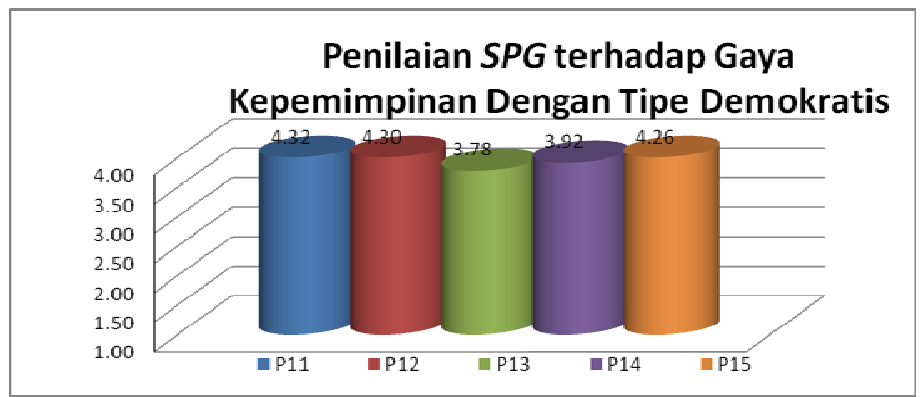

Gambar 3 Gaya Kepemimpinan dengan Tipe Demokratis

P11 berarti berdasarkan Gambar 3, SPG menilai sangat setuju $(4,32)$ pimpinan mereka menghargai pendapat mereka. Dalam P12, berdasarkan Gambar 3, SPG menilai sangat setuju $(4,30)$ pimpinan mereka dapat menjaga hubungan kerja yang ramah dengan mereka. P13 berarti berdasarkan Gambar 3, SPG menilai setuju $(3,78)$ pimpinan mereka bertindak dengan cara mempertimbangkan kepentingan mereka secara pribadi. P14 pada Gambar 3, SPG menilai setuju $(3,92)$ pimpinan mereka mudah diajak bernegosiasi. P15 pada gambar 3, SPG menilai sangat setuju $(4,26)$ pemimpin mereka memberikan kebebasan dalam memberikan ide-ide.

\section{Analisa Kinerja SPG PD Sumber Jaya}

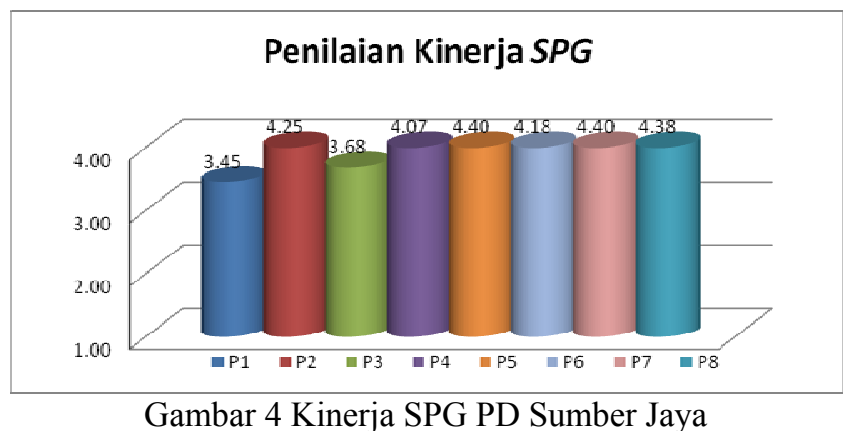

P1 pada Gambar 4 berarti SPG menilai setuju $(3,45)$ mereka dapat mencapai target sesuai dengan yang diinginkan oleh pimpinan mereka. P2 berarti berdasarkan Gambar 4, SPG menilai sangat setuju $(4,25)$ mereka dapat menyelesaikan semua pekerjaan sebaik mungkin untuk memperoleh hasil yang maksimal. P3 pada Gambar 4, SPG menilai setuju $(3,68)$ mereka dapat menghasilkan pekerjaan dengan kualitas yang sesuai dengan keinginan atasan. P4 pada Gambar 4, SPG menilai sangat setuju 
$(4,07)$ pekerjaan dapat mereka selesaikan dengan tuntas dengan kualitas yang baik. P5 berarti berdasarkan Gambar 4, SPG menilai sangat setuju $(4,40)$ mereka berusaha hadir ke-counter tepat waktu setiap hari. P6 pada Gambar 4, SPG menilai sangat setuju $(4,18)$ mereka berusaha agar tidak ada absen dalam pekerjaan mereka. P7 pada Gambar 4, SPG menilai sangat setuju $(4,40)$ mereka tidak suka menunda-nunda pekerjaan yang seharusnya dapat diselesaikan dengan cepat. P8 berarti berdasarkan Gambar 4, SPG menilai sangat setuju $(4,38)$ mereka berusaha dengan serius dalam menyelesaikan suatu pekerjaan dengan cepat dan tepat sampai tuntas.

\section{Analisis Korelasi Antara Gaya Kepemimpinan Terhadap Kinerja SPG}

Tabel 9 Korelasi Gaya Kepemimpinan Terhadap Kinerja SPG Correlations

\begin{tabular}{|ll|l|r|}
\hline & & $\begin{array}{l}\text { Gaya } \\
\text { Kepemimpinan }\end{array}$ & Kinerja SPG \\
\hline Gaya & Pearson Correlation & 1 & .442 \\
& & & .032 \\
& Sig. (2-tailed) & 73 & 73 \\
Kinerja SPG & N & .442 & 1 \\
& Pearson Correlation & .032 & \\
& Sig. (2-tailed) & 73 & 73 \\
\hline
\end{tabular}

Sumber : Hasil Pengolahan Data, 2010

Berdasarkan Tabel 9, bahwa besarnya hubungan gaya kepemimpinan (X) terhadap kinerja $S P G$ (Y) yang dihitung dengan koefisien korelasi adalah 0.442 atau $\left(r_{Y X}=0.442\right)$. Hal ini menunjukkan hubungan yang cukup kuat antara gaya kepemimpinan dengan kinerja SPG. Koefisien korelasi bertanda $(+)$, artinya hubungan antara gaya kepemimpinan terhadap kinerja SPG searah, sehingga jika gaya kepemimpinan naik maka kinerja SPG juga ikut naik. Sumbangan gaya kepemimpinan terhadap kinerja $S P G$ adalah sebesar $K P=r^{2} \times 100 \%=0.442^{2} \times 100 \%=19.50 \%$. Artinya sumbangan $19.50 \%$ variabel kinerja $S P G$ ini dipengaruhi oleh variabel gaya kepemimpinan manajer dan sisanya $80.50 \%$ ditentukan oleh variabel lain yang tidak dapat dijelaskan dalam penelitian ini.

\section{Analisa Pengaruh Gaya Kepemimpinan terhadap Kinerja SPG PD Sumber Jaya}

Tabel 10 Koefisien Regresi Sederhana Gaya Kepemimpinan terhadap Kinerja SPG

\begin{tabular}{|c|c|c|c|c|c|c|}
\hline \multirow{2}{*}{\multicolumn{2}{|c|}{ Model }} & \multicolumn{2}{|c|}{$\begin{array}{c}\text { Unstandardized } \\
\text { Coefficients }\end{array}$} & \multirow{2}{*}{$\begin{array}{c}\text { Standardized } \\
\text { Coefficients } \\
\text { Beta } \\
\end{array}$} & \multirow[b]{2}{*}{$\mathrm{T}$} & \multirow[b]{2}{*}{ Sig } \\
\hline & & B & Std. Error & & & \\
\hline & (Constant) & 31.916 & 3.003 & & 8.975 & .000 \\
\hline & $\begin{array}{l}\text { Gaya } \\
\text { Kepemimpinan }\end{array}$ & .328 & .277 & .442 & 1.855 & .032 \\
\hline
\end{tabular}

a. Dependent Variable: Kinerja SPG

Sumber : Hasil Pengolahan Data, 2010 
Hasil pengolahan data yang diperoleh dalam Tabel 10 di atas dapat ditulis dengan suatu persamaaan regresi dengan model taksiran sebagai berikut:

$$
Y=31.916+0.328 X
$$

Dari persamaan di atas dapat dijelaskan beberapa hal yakni: (1) dari persamaan linear sederhana diatas dapat dilihat besarnya konstanta adalah 31.916 , berarti peningkatan kinerja SPG, saat gaya kepemimpinan tidak ada (nol), maka besarnya adalah 31.916; (2) variabel gaya kepemimpinan (X) bertanda positif menunjukkan adanya hubungan yang searah antara gaya kepemimpinan (X) dengan kinerja SPG (Y). Koefisien regresi variabel gaya kepemimpinan sebesar 0.328. Artinya semakin tinggi gaya kepemimpinan yang dimiliki oleh manajer PD. Sumber Jaya, maka kinerja SPG berkecenderungan akan meningkat.

\section{PENUTUP}

\section{Simpulan}

Dalam penelitian ini, dapat disimpulkan bahwa gaya kepemimpinan manajer PD Sumber Jaya adalah tipe demokratis. Secara individual, gaya kepemimpinan memiliki hubungan yang cukup kuat yaitu sebesar 0.442 terhadap kinerja SPG PD Sumber Jaya. Dan memiliki pengaruh yang signifikan yaitu sebesar 0.195 atau sebesar $19.50 \%$ terhadap kinerja SPG PD. Sumber Jaya. Artinya, gaya kepemimpinan di PD. Sumber Jaya berpengaruh terhadap kinerja $S P G$.

\section{Saran}

Manajer PD Sumber Jaya sebaiknya mempertahankan gaya kepemimpinan yang dijalaninya yaitu gaya kepemimpinan serta meningkatkan kinerja kepemimpinannya untuk lebih baik lagi. Dan Manajer PD. Sumber Jaya pun harus dapat menumbuhkan hubungan kerja yang lebih bersahabat dengan SPG. Karena hubungan yang baik antara manajer dengan SPG sangat penting didalam menunjang kinerja SPG. Manajer PD Sumber Jaya sebaiknya mencari faktor-faktor lain yang dapat meningkatkan kinerja SPG selain dari gaya kepemimpinan dan motivasi agar dapat meningkatkan kinerja SPG dan berdampak pada meningkatnya penjualan dan kinerja perusahaan.

\section{DAFTAR PUSTAKA}

Davis, K. and Newstrom, J. W. (1985), Perilaku dalam Organisasi, Jakarta: Erlangga

Kartono, K. (2006). Pemimpin dan kepemimpinan. Jakarta: Raja Grafindo Persada.

Luthans, F. (2006). Perilaku organisasi (10th ed.). Yogyakarta: Andi.

Rivai, V., \& Mulyadi, D. (2009). Kepemimpinan dan perilaku organisasi (2nd ed.). Jakarta: Raja Grafindo Persada.

Robbins, S. P., \& Judge, T. A. (2008). Organizational Behaviour (13th ed.). Prentice Hall. 
Sekaran, U. (2006). Metodologi penelitian untuk bisnis, Jilid 1 (4th ed.). Jakarta: Salemba Empat. Sekaran, U. (2006). Metodologi penelitian untuk bisnis, Jilid 2 (4th ed.). Jakarta: Salemba Empat. Thoha, M. (2007). Kepemimpinan dalam manajemen. Jakarta: Raja Grafindo Persada. 